Kalpa Publications in Civil Engineering
Volume 1, 2017, Pages 478-483
$\begin{gathered}\text { ICRISET2017. International Conference on Re- } \\ \text { search and Innovations in Science, Engineering } \\ \text { \&Technology. Selected papers in Civil Engineering }\end{gathered}$

\title{
Comparative Study of Direct Displacement Based and Forced Based Design Method for RC- Frame with Shear Wall
}

\author{
Bijal S Chaudhri ${ }^{1}$ Dipali Patel ${ }^{2 *}$ \\ ${ }^{1}$ M.tech student, Civil and structural engineering, CHARUSAT, Changa, India \\ ${ }^{2}$ Assistant Professor, CHARUSAT, Changa, India \\ Bijalchaudhri93@gmail.com, Dipalipatel.cv@charusat.ac.in
}

\begin{abstract}
The Seismic design of structure has conventionally been force based. Displacement is the major factor for the damage rather than force. The alternative procedure for seismic design, which becomes more popular, is performance based design method. Displacement is global parameter of performance based design method. Direct displacement based design method has been used for seismic design of structure. The paper attempts to design moment resisting RC-frame using Displacement based design method and Forced based design method. 15-storey building with shear wall has been taken for parametric study. The parameter like base shear and lateral load distribution are taken for the study. It is observed that base shear of RC building calculated by DDBD is less compared to FBD.
\end{abstract}

\section{Introduction}

Earthquakes are sudden shaking event caused by movement of tectonic plates under the earth surface, which release energy in earth's crust that creates seismic waves. Earthquakes are predominant and most destructive forces, which damage the structure. The aim is to evaluate earthquake force (base shear) to minimize the damage in structure. The Seismic design of structure has traditionally been force based. The performance based design is an alternative approach for the seismic design of structure. Direct displacement based design is based on performance based design.

Direct displacement based design (DDBD) is proposed by priestly (1993). The basic goal of DDBD is to obtain a target displacement profile when the structure is subjected to earthquake ${ }^{[1]}$. This method is simple design approach for analysis of multi-degree freedom system. In this method, the secant stiffness and equivalent damping of an equivalent single degree of freedom system identify the structure. The strength at assigned plastic hinge location to obtain target displacement is determined by DDBD approach ${ }^{[5]}$. 
Priestley and Kowalsky (2000) discussed displacement based seismic design of concrete building. This method accomplished design for structure to satisfy pre-defined drift level in a direct manner. In this design procedure, code drift, inelastic rotation capacities of the structure, initial stiffness are the parameter. This method uses displacement profile of structure to determine the system displacement. The multi storey frame and wall buildings are taken for the analysis purpose. The target displacements are correlated with results from inelastic time history analysis. From the analysis, it is observed that the required base shear strength in DDBD method proportional to square of seismic intensity ${ }^{[4]}$.

\section{Geometry of Building}

The 15-storey RC moment resisting frame with shear wall has been taken. The building design of FBD approach is done using IS $1893: 2002^{[2]}$. The geometry of building is shown in Figure 1 . The storey height of building is $3.2 \mathrm{~m}$. It is located in Zone-V and constructed on medium type of soil. The response reduction factor $(\mathrm{R})$ of building is 5 and Importance factor (I) has been take as 1 . The other building specification is shown in Table 1

\begin{tabular}{cll}
\hline Sr no. & \multicolumn{1}{c}{ Elements } & \multicolumn{1}{c}{ Description } \\
\hline 1 & Slab thickness & $125 \mathrm{~mm}$ \\
2 & Imposed load & $2.50 \mathrm{kN} / \mathrm{m} 2$ \\
3 & Floor finish & $1.00 \mathrm{kN} / \mathrm{m} 2$ \\
4 & Wall load & $15 \mathrm{kN} / \mathrm{m}$ (All storey) \\
& & $5 \mathrm{kN} / \mathrm{m}$ (Roof) \\
5 & Concrete grade & M25 \\
\hline
\end{tabular}

Table 1: Building specification

The building was designed for following load combination: (a) 1.5(DL+LL) (b) 1.2(DL+LL \pm EL) (c) 1.5(DL $\pm E L)$ as per IS 456:2000[6]. The spectral acceleration and displacement spectra were used as per IS 1893 (part-I): 2002 for medium soil of 5\% damping. To compare the base shear for DDBD and FBD approach, the dead load of the building has been kept same and the beam-column sizes are shown in Table 2. 


\begin{tabular}{lcl}
\hline & Beam sizes $(\mathrm{mm})$ & \\
\hline & FBD & DDBD \\
All stories & $400 \times 600$ & $400 \times 600$ \\
\hline & Column sizes $(\mathrm{mm})$ & DDBD \\
\hline & $600 \times 900$ & $600 \times 900$ \\
1 storey & $600 \times 800$ & $600 \times 800$ \\
2 storey & $600 \times 700$ & $600 \times 700$ \\
$7,4,5$ and 6 storey & $600 \times 600$ & $600 \times 600$ \\
$9,10,11$ and 12 storey & $450 \times 600$ & $450 \times 600$ \\
13,14 and 15 storey & $450 \times 450$ & $450 \times 450$ \\
Shear wall & $5000 \times 200$ & $5000 \times 200$ \\
\hline
\end{tabular}

Table 2: Beam and Column Sizes for Building

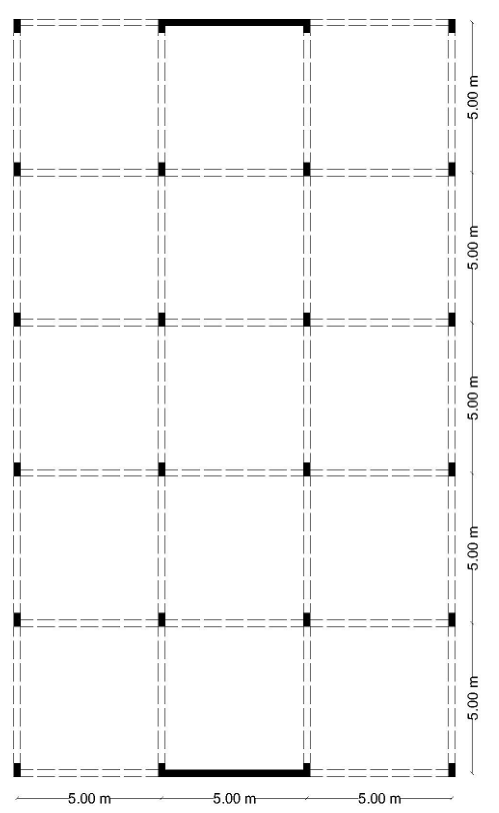

Figure 1: Geometry of Building

\section{Design of RC-frame Building using DDBD and FBD method}

The calculated parameters for design of 15- storey building using DDBD method are as follow: 
Total seismic weight $=96830.06 \mathrm{kN}$

Frame shear ratio, $B F=0.25$

Height of contraflexure, $\mathrm{HCF}=33.92 \mathrm{~m}$

Design displacement, $\Delta \mathrm{d}=0.52 \mathrm{~m}$

Effective height, $\mathrm{He}=33.87 \mathrm{~m}$

Equivalent viscous damping, $\xi_{\text {sys }}=12.00 \%$

Time period, $\mathrm{Te}=6.50 \mathrm{Sec}$.

Effective mass, me $=7029.40$ tonne

Effective stiffness, $\mathrm{ke}=6561.62 \mathrm{kN} / \mathrm{m}$

Base shear, $\mathrm{Vb}=3410.89 \mathrm{kN}$

The percentage of reinforcement in beam and column of 15-storey building designed by FBD and DDBD approach are presented in Table 3.

\begin{tabular}{|c|c|c|c|c|c|c|c|c|c|c|c|c|}
\hline \multirow{4}{*}{$\stackrel{\grave{d}}{\stackrel{\Xi}{\Delta}}$} & \multicolumn{6}{|c|}{$\mathrm{Pt}(\%)$ of reinforcement for FBD } & \multicolumn{6}{|c|}{$\mathrm{Pt}(\%)$ of reinforcement for DDBD } \\
\hline & \multicolumn{4}{|c|}{ Beam } & \multirow{3}{*}{$\begin{array}{c}\text { Col } \\
\text { um } \\
\text { n }\end{array}$} & \multirow{3}{*}{$\begin{array}{c}\text { Shea } \\
\text { r } \\
\text { wall }\end{array}$} & \multicolumn{4}{|c|}{ Beam } & \multirow{3}{*}{$\begin{array}{c}\text { Colu } \\
\mathrm{mn}\end{array}$} & \multirow{3}{*}{$\begin{array}{l}\text { Shear } \\
\text { wall }\end{array}$} \\
\hline & \multicolumn{2}{|c|}{ Start } & \multicolumn{2}{|c|}{ End } & & & \multicolumn{2}{|c|}{ Start } & \multicolumn{2}{|c|}{ End } & & \\
\hline & Top & Bot. & Top & Bot. & & & Top & Bot. & Top & Bot. & & \\
\hline 15 & 0.35 & 0.29 & 0.29 & 0.29 & 2.39 & 0.27 & 0.23 & 0.12 & 0.23 & 0.12 & 1.25 & 0.25 \\
\hline 14 & 0.63 & 0.32 & 0.29 & 0.29 & 2.37 & 0.27 & 0.55 & 0.28 & 0.55 & 0.28 & 1.50 & 0.25 \\
\hline 13 & 0.64 & 0.32 & 0.29 & 0.29 & 2.55 & 0.27 & 0.71 & 0.35 & 0.71 & 0.35 & 2.12 & 0.25 \\
\hline 12 & 0.72 & 0.36 & 0.29 & 0.29 & 1.70 & 0.27 & 0.65 & 0.25 & 0.25 & 0.25 & 2.50 & 0.25 \\
\hline 11 & 0.72 & 0.36 & 0.29 & 0.29 & 2.18 & 0.27 & 0.71 & 0.31 & 0.71 & 0.31 & 2.67 & 0.25 \\
\hline 10 & 1.2 & 0.79 & 1.04 & 0.87 & 2.58 & 0.27 & 0.92 & 0.35 & 0.92 & 0.35 & 2.89 & 0.25 \\
\hline 9 & 1.28 & 0.90 & 1.15 & 0.98 & 3.12 & 0.27 & 0.83 & 0.38 & 0.91 & 0.45 & 2.50 & 0.25 \\
\hline 8 & 1.36 & 1.01 & 1.24 & 1.01 & 2.26 & 0.40 & 1.12 & 0.42 & 1.09 & 0.45 & 2.80 & 0.25 \\
\hline 7 & 1.42 & 1.09 & 1.31 & 1.15 & 2.60 & 0.40 & 1.36 & 0.65 & 1.36 & 0.65 & 2.75 & 0.38 \\
\hline 6 & 1.43 & 1.13 & 1.33 & 1.18 & 1.87 & 0.41 & 1.24 & 0.91 & 1.15 & 0.89 & 2.00 & 0.32 \\
\hline 5 & 1.46 & 1.16 & 1.37 & 1.21 & 2.22 & 0.45 & 1.21 & 0.78 & 1.11 & 0.62 & 2.90 & 0.59 \\
\hline 4 & 1.46 & 1.17 & 1.39 & 1.21 & 2.57 & 0.78 & 1.13 & 0.71 & 1.21 & 0.71 & 2.78 & 0.68 \\
\hline 3 & 1.43 & 1.16 & 1.38 & 1.19 & 2.88 & 1.45 & 1.24 & 0.61 & 1.17 & 0.65 & 2.80 & 1.01 \\
\hline 2 & 1.42 & 1.02 & 1.18 & 1.12 & 2.37 & 1.47 & 1.35 & 0.81 & 1.29 & 0.72 & 2.01 & 1.28 \\
\hline 1 & 1.01 & 0.66 & 0.86 & 0.70 & 2.88 & 1.80 & 0.81 & 0.36 & 0.79 & 0.31 & 2.50 & 1.60 \\
\hline
\end{tabular}

Table 3: Reinforcement Percentage for DDBD and FBD method 


\section{Comparison of Result}

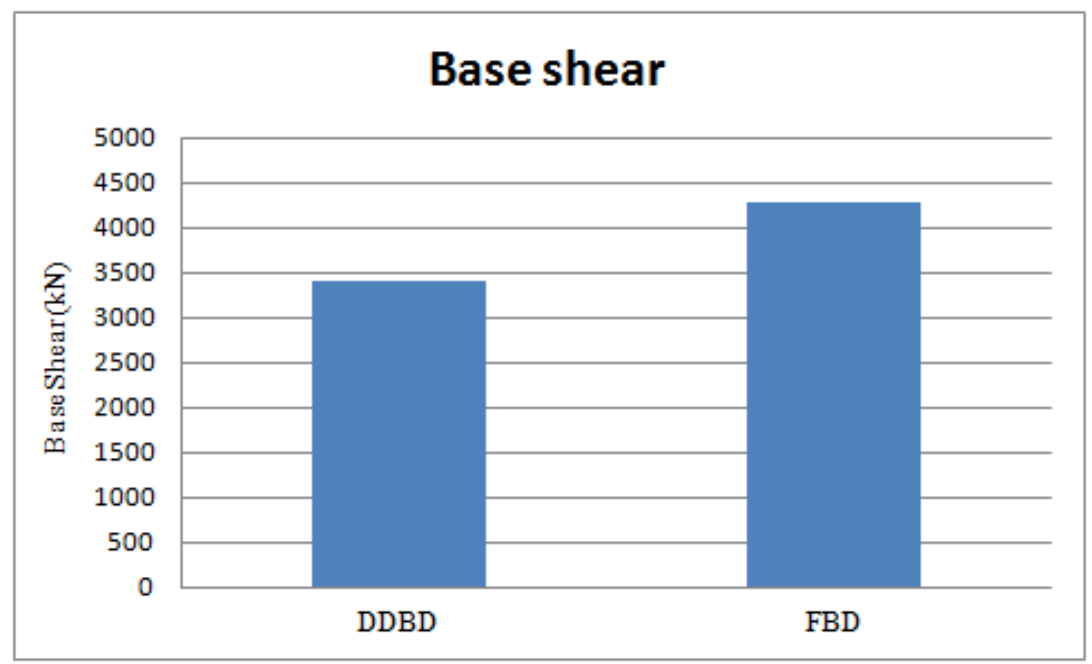

Figure 2: Base shear for $\mathrm{G}+15$ building

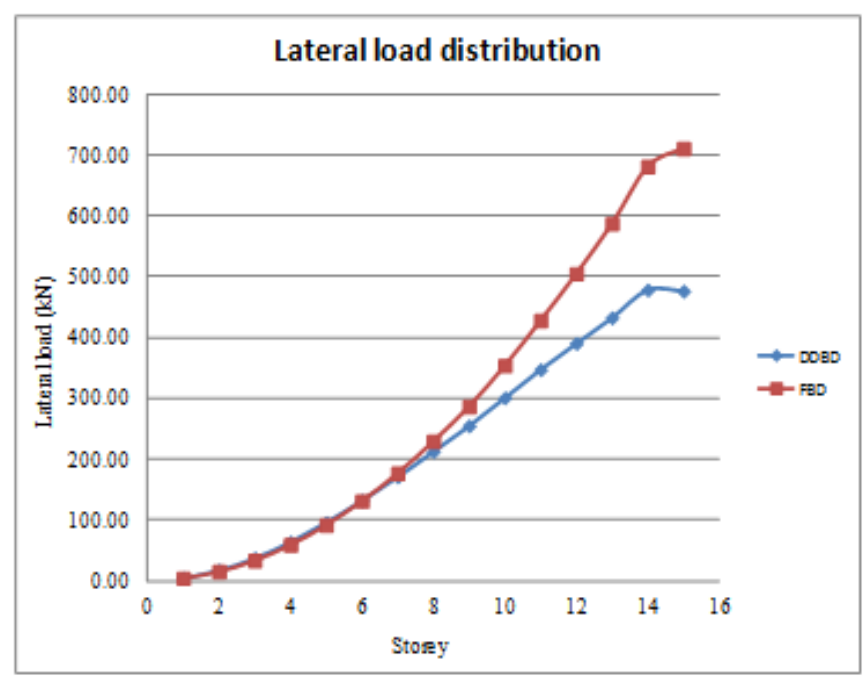

Figure 3: Lateral force distribution for $\mathrm{G}+15$ building

The result of base shear comparison for both approaches is shown in Figure 2. It is observed that the base shear for DDBD structure is less compare to FBD structure. This is due to DDBD structure does not depend on empirical time period formula for time period for calculation of base shear. The result of lateral load distribution is show in Figure 3 for DDBD and FBD method.

\section{Conclusion}

After the design carried out for G+ 15 building using Force based design method and direct displacement based design method, the following conclusions are derived: 
The base shear of DDBD structure is reduced by $25.70 \%$ compare to FBD structure. It is clearly observed from lateral load distribution that the lateral loads are less in DDBD compare to FBD. Also, from the calculations of percentage reinforcement it is seen that less percentage of steel is required in DDBD as compare to FBD.

Above points prove that DDBD approach is more effective compare to FBD approach.

\section{References}

M.J.N .Priestley, G.M.Calvi, M.J. Kowalsky: Displacement-based seismic design of structure, IUSS Press

IS 1893: 2002 (2002): Criteria for Earthquake Resistance Design of Structures, BIS, New Delhi.

M.J.N. Priestley, D.N Grant, C.A. Blandon, "Direct displacement based seismic design", 2005, NZSEE

M.J.N. Priestley, M.J. Kowalsky (2000): Direct displacement based seismic design of concrete building, Bulletin of the new Zealand society for earthquake engineering, Vol. 33, No. 4

M.J.N. Priestley, G.M .Calvi, M.J. Kowalsky (2008): Displacement-Based Seismic Design of Structure.

IS 456: 2000 (2000): Plain and reinforced concrete- code of practice. BIS, New Delhi

R. K. Sheth, D. P. Soni (2016): Performance evaluation of RC moment resisting frames designed by direct displacement design in light of IS code. Journal of structural engineering, Vol. 42, No.6, pp. 528-539 